\begin{tabular}{|l|l|l|l|l|l|l|}
\hline InterteXto & Uberaba & UFTM & v. 1 & p. 186-208 & 2008 - jan. / jun. & ISSN 1981-0601 \\
\hline
\end{tabular}

\title{
A IMPORTÂNCIA DOS CAMPOS LÉXICOS NO ENSINO DE LÍNGUA PORTUGUESA
}

\author{
THE IMPORTANCE OF THE LEXICAL FIELDS IN THE TEACHING OF \\ PORTUGUESE LANGUAGE
}

Sheila de Carvalho Pereira ${ }^{1}$

\begin{abstract}
Resumo
Este artigo tem o objetivo de apresentar uma breve discussão sobre o ensino da Língua Portuguesa, em especial, o ensino e aprendizagem do vocabulário, tendo como embasamento a teoria dos Campos Léxicos, que pode contribuir para a adequação e aprimoramento das atividades em sala de aula. Acreditamos que discussões e pesquisas sobre o ensino e enriquecimento vocabular do aluno, pelo viés da Lexicologia e privilegiando a Teoria dos Campos Léxicos, podem trazer importantes contribuições para a mudança na forma de tratamento do vocabulário e, conseqüentemente, no ensino da Língua Portuguesa. Vale ressaltar que esse trabalho é parte do resultado das inúmeras reflexões realizadas durante a pesquisa de Mestrado.
\end{abstract}

Palavras-chave: Ensino-aprendizagem; Língua Portuguesa; Teoria dos Campos Léxicos.

\begin{abstract}
The aim of this work is to provide a brief discussion on Portuguese Language teaching, especially, the teaching and learning of vocabulary, based on the Lexical Field Theory, which can contribute to the adequacy and improvement of the activities in classroom. We believe that discussion and researches on teaching and improvement of the student's vocabulary, by means of Lexicology and with focus on the Lexical Field Theory, can bring important contributions to change the way of approaching the vocabulary and, consequently, the way of teaching the Portuguese Language. It is worth noting that this work is part of the results derived from a Master degree research.

Key-words: Teaching-learning; Portuguese Language; Lexical Field Theory.
\end{abstract}

\section{INTRODUÇÃO}

Muito tem se discutido sobre o ensino e aprendizagem da Língua Portuguesa. Certamente, são numerosos e constantes os desafios encontrados tanto pelo professor, quanto pelo aluno. Talvez, seja por isso que, infelizmente,

(1) Doutoranda em Lingüística (UNESP-Rio Preto), professora de Português Instrumental e Lingüística da UNIPAC - Universidade Presidente Antônio Carlos Faculdade de Ciências Sociais, Letras e Saúde de Uberlândia-MG. sheilacpgoncalves@yahoo.com.br 
as aulas de Língua Portuguesa ainda são oportunidades desperdiçadas de se pensar em uma prática que possa despertar e auxiliar o aluno a resgatar o seu próprio idioma.

Por culpa de métodos ineficientes, de posturas errôneas e indefinição de objetivos ainda é presente uma metodologia que não permite ao aluno estabelecer ligações entre o que se aprende na escola e o que se vive fora dela.

Dessa forma, este artigo tem como objetivo discutir o ensino e aprendizagem do vocabulário no Ensino Fundamental. Inicialmente, para melhor organização do texto, tecemos algumas considerações sobre a importância da palavra e a necessidade de sabermos revelar seus enigmas, buscando descrever com clareza e precisão os seus significados. Logo após, fundamentamos nossa análise em alguns estudos que abordam conceitos fundamentais da Lexicologia e, em especial, a teoria dos Campos Léxicos. Depois, procuramos, de forma sucinta, explicar como esses pressupostos poderiam contribuir para a adequação e aprimoramento das atividades para o ensino e aprendizagem do léxico.

\section{A IMPORTÂNCIA DA PALAVRA}

"As palavras não são outra coisa do que vozes destinadas, pelo uso dos homens, a significar as coisas... As palavras, pois, terão de fazer um retrato perfeito das idéias que significam."

Luzán

Indissolúvel é a ligação entre a linguagem e a vida. Vivemos, fazemos, utilizamos e somos palavras. De nossos mais recônditos sonhos às mais diversas situações do dia, as palavras atravessam praticamente todas as dimensões da nossa existência. Afinal, é por meio dela que podemos expressar o que fazemos, o que sonhamos e o que sentimos. 
Em muitos momentos, utilizamos as palavras para organizar e esclarecer as nossas próprias idéias, para dar sentido ao nosso pensamento e nos fazer entender. Além disso, ao escrever, em inúmeras vezes, não conseguimos expressar nossas idéias e emoções através das palavras.

Partindo do pressuposto de que ela é o instrumento de que precisamos para entrar em contato com os mais diversificados textos é necessário saber lidar bem com elas, desvendar os seus segredos, produzir sentidos, descrever com clareza e precisão os seus significados.

Sem sombra de dúvidas, podemos afirmar que toda a história do homem sobre a terra constitui em um esforço permanente de comunicação. Ela se tornou fundamental da reunião em famílias à comunidade e ao trabalho. O nível de progresso nas sociedades humanas tem como um de seus fatores primordiais a maior ou menor capacidade de comunicação entre seus povos.

Estamos imersos em uma sociedade que vem vivendo profundas transformações desde a invenção da escrita (uma das mais extraordinárias conquistas do homem) à popularização do cinema, rádio, tevê e a internet.

Socialmente, o léxico é transmitido de geração a geração. E, nesse mundo em movimento, os estudos relativos à linguagem, em especial, o ensino do vocabulário sempre possuiu um lugar de destaque, pois é a partir da palavra que nomeamos a realidade.

Ao utilizar as palavras, os falantes recorrem a um sistema lingüístico e elaboram seus discursos, que se materializam em textos. Portanto, podemos afirmar que o léxico é a primeira passagem que nos coloca em contato com um texto. Dessa forma, ele é o indicador mais seguro dos obstáculos que nos impedem de compreender e interpretar um texto, pois uma quantidade considerável de conhecimentos é empregada toda vez que o aluno se propõe a definir e/ou utilizar uma palavra.

Nesse sentido, consideramos que essa nossa reflexão oferecerá subsídios para a reflexão e a adoção de posturas que minimizem a distância entre a teoria e as situações concretas de aprendizagem; partirá do princípio de 
que o vocabulário, assim como o conhecimento, é adquirido de forma gradual pelo aluno, partindo de palavras de maior freqüência e que pertençam ao contexto em que ele esteja inserido; será um ensino centrado no aluno, privilegiando, dessa forma, o público-alvo.

Acreditamos que discussões e pesquisas sobre 0 ensino e enriquecimento vocabular do aluno, pelo viés da Lexicologia e privilegiando a Teoria dos Campos Léxicos, poderão trazer importantes contribuições para a mudança na forma de tratamento do vocabulário e, conseqüentemente, no ensino da Língua Portuguesa. Passemos, então, à teoria que embasará as nossas discussões.

\section{TEORIA DOS CAMPOS LÉXICOS: CONCEITOS BÁSICOS}

Conforme mencionado anteriormente, a necessidade de se nomear elementos da realidade é uma constante na vida do homem, pois o léxico está em constante modificação. Sabemos que esse processo de expansão se dá de diferentes formas. Dentre as inúmeras opções para se estudar o léxico, a análise através de campos tem se destacado, recebendo várias denominações: campos semânticos, campos léxicos, campos conceptuais, campos nocionais.

Partindo do pressuposto de que a significação de um item lexical decorre do contexto e da premissa de que toda palavra envolve uma rede de traços semânticos e, por isso, integra um determinado campo de significação, é que optamos pela denominação campo léxico.

Segundo Saussure (1972), os signos, num sistema lingüístico, têm existência real na medida em que estiverem relacionados uns com os outros, o que ocorre tanto no nível sintagmático como paradigmático.

É importante citar que as pesquisas voltadas para o léxico remontam da Antigüidade Clássica, mas apenas no século $X X$, essa concepção passou a ganhar mais valor. Podemos afirmar que o princípio da solidariedade entre as palavras, ou seja, a noção de "rede associativa", defendida por Saussure, 
motivou muitos estudiosos, que acabaram por dar origem à Teoria dos Campos léxicos.

Muitos princípios defendidos pelo célebre autor, tais como "sistema", "valor", relações paradigmáticas", relações sintagmáticas", posteriormente sedimentaram a teorização sobre campo.

No interior de uma mesma língua, todas as palavras que exprimem idéias vizinhas se limitam reciprocamente: sinônimos como recear, temer, ter medo só têm valor próprio pela oposição; se recear não existisse, todo seu conteúdo iria para os seus concorrentes. (SAUSSURE, 1972, p. 135).

No entanto, segundo Lyons (1980, a teoria dos campos léxicos, na sua forma original, foi proposta por alguns lingüistas durante as décadas de 1920 e 1930: Ipsen (1934), Porzig (1934), Trier (1934)

Trier (1934) foi quem primeiro sistematizou e fundamentou em Humboldt e em Saussure a teoria. O autor buscou nas idéias de Saussure a idéia de língua como sistema, aproveitando esse princípio de forma sistemática na investigação do léxico. Trier defendeu que as palavras de uma língua formam uma globalidade articulada, ou melhor, uma estrutura formada de determinados domínios parciais que se subordinam a um todo. Exatamente a esse domínio que se situa no nível intermediário entre a palavra individual e o léxico total, ele denominou de campos. Para ele

\footnotetext{
Campos son lãs realidades lingüísticas vivas, situadas entre lãs palabras individuales y el conjunto Del vocabulario, que, en cuanto totalidades parciales, tienen como característica común con la palabra el articularse [ergliedern] y, con el vocabulario, el organizarse [ausgliedern]. El grado jerárquico es indiferente (TRIER apud GECKELER, 1976, p. 123.).
}

Trier considera o vocabulário de uma língua um todo semanticamente articulado e estruturado em campos, que podem estar ligados entre si por relações de coordenação ou hierarquia. Para o autor há diferenças entre 
campo léxico e conceitual: o campo léxico divide o campo conceitual em partes, tal qual um mosaico. A palavra adquire seu significado pela oposição em face de outras palavras próximas ao campo.

$\mathrm{Na}$ década de 1930, segundo Geckeler (1976),Weisgerber (1954) associou-se a Trier, trazendo aos estudos sobre campos importantes considerações. Entretanto, foi Porzig quem desenvolveu uma perspectiva teórica oposta ao seu contemporâneo Trier. Enquanto este priorizou as relações paradigmáticas, aquele focalizou as relações sintagmáticas. $\mathrm{E}$ a Porzig que cabe o mérito de ter sublinhado que a abstração e a generalização dependem do afrouxamento das relações sintagmáticas entre lexemas e de ter demonstrado que estas relações, tal como as relações paradigmáticas de sentido, determinam a estrutura de um campo léxico (LYONS, 1980, p. 214).

Em suas pesquisas, o autor procurou fazer um levantamento de unidades lexicais relacionadas com a idéia de "conhecimento", em alemão. Na verdade, foi um trabalho que buscava introduzir os ensinamentos de Saussure, mostrando que os campos colocam em evidência os setores entrelaçados do vocabulário, onde cada elemento delimita seu vizinho e é por ele delimitado.

Como sucessor, Leo Weisgerber (1954) também se apoiou nas idéias de Trier, tendo os dois trabalhos como característica principal a grande influência de W. Von. Humboldt sobre a concepção de língua e de campo. A essência da idéia humboldtiana é a de que a articulação é a característica mais geral e mais profunda de toda língua. Para Humboldt, dizer que uma palavra em uma língua é "articulada" significa referi-la ao sistema de elementos subjacentes a partir dos quais ela é construída; elementos que poderiam ser usados para formar infinitas outras palavras, de acordo com intuições e regras definidas. É neste sentido que uma palavra é um "objeto articulado", apreendida na percepção pelo exercício da "capacidade humana, forjadora da linguagem" mais do que por algum processo simplesmente análogo à "capacidade sensitiva animal". 
Humboldt destacava que a linguagem é uma constante e dinâmica criação do espírito humano. Para o autor, o falante faz uso infinito da língua, empregando recursos finitos, ou seja, diante de um número limitado de regras é capaz de produzir um número ilimitado de sentenças.

Segundo Trier (1934) a existência da articulação lingüística em campos não é produto da fantasia humana ou de uma hipótese lingüística, mas sim o resultado do esforço humano em representar conceptualmente a realidade extralingüística, que é, infinitamente articulada. A partir destas constatações, Jost Trier e Leo Weisgerber aplicaram as idéias de Ferdinand de Saussure. Segundo a concepção saussuriana, "a língua é um todo organizado, cujos elementos se delimitam uns aos outros, derivando a sua significação, o seu valor da arquitetura geral em que estão colocados" (SAUSSURE, 1972, p. 134).

Vários são os enfoques dados à Teoria dos Campos Léxicos, não apenas no que diz respeito à terminologia, como também às perspectivas de abordagem.

Genouvrier \& Peytard (1973) determinam que campo léxico

é o conjunto das palavras que a língua agrupa ou inventa para designar os diferentes aspectos (ou os diferentes traços semânticos) de uma técnica, de um objeto, de uma noção: campo lexical do "automóvel", da "aviação", da "álgebra", da "moda", da "idéia de Deus" etc.

E, para os autores, campo semântico

é o conjunto dos empregos de uma palavra (ou sintagma, ou lexia) onde e pelos quais a palavra adquire uma carga semântica específica. Para delimitar esses empregos, faz-se o levantamento de todos os contextos imediatos que a palavra recebe num texto dado.

Na obra de Pottier (1974), nota-se a preocupação de conciliar a tradição gramatical com visões novas a respeito da língua, especialmente no que diz respeito à semântica. Para o autor, a dimensão do signo lingüístico parte do 
morfema, onde se centra a semântica, da oração em busca do texto. Ele acredita que, embora o dicionário não registre exatamente o total de palavras, é o retrato de momentos da língua. Como a linguagem é usada pelos falantes, ela acaba recebendo alterações nos significados das palavras. Mudanças essas que podem levar anos ou séculos. Sendo assim, o dicionário pode apresentar significações passadas, presentes e até mesmo significações possíveis dentro de um sistema lingüístico.

Importantes contribuições foram dadas por Eugênio Coseriu (1977), que situou sua investigação ao nível da língua, da linguagem primária, da sincronia, da técnica do discurso, da língua funcional, do sistema da significação e da significação lexical. Excluiu, portanto, tudo o que estivesse relacionado com o discurso ou com o texto: a designação, o sentido, as significações categorial e instrumental, os significados frásico e sintático.

Concluiu que o significado lexical é autônomo e deverá ser tratado autonomamente. Coseriu determinou como princípios básicos que devem nortear a análise lexical: a funcionalidade, a oposição, a sistematicidade e a neutralização.

Assim, Coseriu (1977) define campo léxico:

um campo léxico é do ponto de vista estrutural, um paradigma léxico que resulta da repartição de um conteúdo léxico contínuo entre diferentes unidades dadas na língua como palavras e que se opõem de maneira imediata umas a outras, por meio de traços distintivos mínimos. (COSERIU, 1977, p. 146).

Para o autor, os itens lexicais no interior de um campo estão em oposição. Esta oposição é uma escolha obrigatória para uma parte dos esquemas de cada língua. Um campo se estabelece onde uma nova oposição exija que o valor unitário do campo se torne traço distintivo, isto é, termina onde não são mais as palavras como tais que se opõem, mas o campo inteiro com seu valor unitário. 
Atinge o máximo de formalização o estruturalismo europeu. $O$ lingüista deve se reservar à delimitação externa e interna dos campos léxicos, até os traços mais íntimos. Nesse sentido ele deverá considerar a análise da palavra no seu todo estruturado. Sendo assim, o significado de um lexema tem traços sêmicos comuns com outros lexemas e distingue-se do de outros traços sêmicos diferentes.

Podemos, então, falar em sinônimos (palavras cujos significados têm traços sêmicos comuns) e antônimos (cujos significados se distinguem por traços diferentes na sua constituição para além do que têm de comum).

Coseriu define campo léxico como uma estrutura paradigmática constituída por unidades léxicas que se dividem em uma zona de significação comum e que se encontram em oposição imediata umas com as outras. Dessa forma, as oposições semânticas de um campo léxico é que determinam suas relações internas, no diz respeito à estrutura de conteúdo.

O autor aponta vários critérios para a tipologia do campo coseriano: inicialmente, tipos de oposições formalmente diferentes podem funcionar num mesmo campo e servem para caracterizar microcampos. Em segundo lugar, mesmo que caracterizem campos inteiros, os tipos formais de oposição servem para distinguir subtipos de campos, mas não os tipos principais que englobam esses subtipos. E, por último, às relações formais internas de um campo pertence também o tipo de relação existente entre os significados e sua expressão.

Coseriu chegou a uma primeira classificação dos campos léxicos, segundo sua configuração, seu objetivo e sua expressão. O autor defende primeiramente que a maneira como os lexemas estão ordenados e se relacionam entre si depende de dimensões semânticas e, em segundo lugar, dos tipos formais de oposições estabelecidas de acordo com essas dimensões.

Segundo Coseriu (1977) um campo léxico, do ponto de vista estrutural, é um paradigma léxico que resulta da repartição de um conteúdo léxico contínuo 
entre diferentes unidades dadas na língua como palavras e que se opõem de maneira imediata umas às outras, por meio de traços distintivos mínimos (COSERIU, 1977, p. 146).

Biderman também reconhece a teoria do relativismo lingüístico no léxico. Para ela, o léxico é o "tesouro vocabular de uma determinada língua", que incorpora a "nomenclatura de todos os conceitos lingüísticos e não-lingüísticos e de todos os referentes do mundo físico e do universo cultural, criado por todas as culturas humanas atuais e do passado" (BIDERMAN, 1981, p. 138).

A autora manifesta-se acerca das questões relativas aos campos léxicos e semânticos, atestando que:

\begin{abstract}
a memória registra, de maneira ordenada, o sistema lexical. A experiência cotidiana comprova a existência de processos mnemônicos, estruturalmente ordenados, de tal forma que quando queremos lembrar de um vocabulário, desencadeia-se um processo que nos fornece, normalmente em série, várias palavras que integram um mesmo subsistema léxico ou então, um determinado campo semântico. (BIDERMAN, 1981, p. 144).
\end{abstract}

Não pretendemos compilar o que os autores têm pesquisado sobre a teoria dos campos Léxicos. Pretendemos sim, enfatizar que, apesar das diferentes nomenclaturas, eles são unânimes em afirmar que as palavras mantêm intrínseca ligação.

Dessa forma, o que nos interessa neste estudo é tomar campo léxico tendo em vista as relações associativas de idéias, associações sinonímicas e antonímicas, bem como os campos de famílias de palavras. Assim, tratamos o ensino e aprendizagem do vocabulário. Passemos, dessa forma, as questões relativas às possíveis contribuições dessa teoria para o ensino da Língua Portuguesa. 


\section{ENSINO E APRENDIZAGEM DE LÍNGUA PORTUGUESA: POSSÍVEIS CONTRIBUIÇÕES}

Retomemos a afirmação de que esse trabalho é resultado das inúmeras reflexões realizadas durante a pesquisa de Mestrado. Buscamos colocar em evidência como tem sido tratado o ensino do vocabulário no referido nível de ensino analisado.

Mostramos a importância da palavra e alguns conceitos relacionados à teoria dos campos Léxicos. Discutiremos, agora, as possíveis contribuições dessa teoria para o ensino e aprendizagem do vocabulário no Ensino Fundamental.

Estamos convictos de que é tarefa da escola, especialmente no mundo globalizado de hoje, ajudar o aluno a ampliar o seu vocabulário para que ele possa se expressar com clareza. Afinal, em geral, todo ser se projeta por meio da linguagem. Além disso, é claro, a escola deve auxiliar o estudante a adquirir a competência para "manejar" a própria língua. Porém, para que esse "manejo" seja continuado e produtivo, é preciso que esteja assentado em bases sólidas.

Além disso, outro ponto que nos chamou a atenção é a pequena importância dada ao estudo do vocabulário e a maneira como esse processo tem sido realizado, na escola. Em uma rápida análise, percebemos que há uma tendência dos livros didáticos em organizar suas lições reunindo aspectos relativos ao ensino e aprendizagem do vocabulário de forma limitada. Freqüentemente, as palavras supostamente desconhecidas pelo aluno são tratadas em um glossário, definidas em uma única acepção, aquela que faz sentido no texto e seu entendimento é assegurado de forma linear e contextual.

Assim sendo, percebe-se que a maioria dos exercícios didáticos que reúnem aspectos relativos ao ensino e aprendizagem do vocabulário, apenas exigem do aprendiz simples automatismos e não requerem nenhuma capacidade cognitiva. 
Uma reflexão sobre essas questões aliada à prática e experiência como professora, no referido nível de ensino analisado, levou-nos a pensar que uma possível explicação para esse fato poderia estar na inadequação das propostas metodológicas utilizadas no ensino do vocabulário, as quais, por vezes, tornam-se atividades estereotipadas, em que o aluno não escreve para interagir com o mundo, mas para dar conta de uma tarefa sem qualquer relação com a sua vida. Se o contrário acontecesse, as atividades de ensino do vocabulário propiciariam a ampliação e a utilização das mais variadas palavras nos mais variados contextos.

Também não podemos deixar de mencionar que o acervo lexical da maioria dos alunos do Ensino Fundamental é ainda insuficiente e deficitário, pois existe uma inabilidade de se conceituar objetos, ações, qualidades, sentidos, termos e ainda suas transferências para contextos diferenciados.

Nossa intenção não é nos posicionarmos contra esse propósito, porém, acreditamos que conhecer o vocabulário de uma língua está entre os fatores determinantes que contribuem para a compreensão de textos, e ele não se reduz à questão do número de palavras desconhecidas pelo aluno e muito menos ao conhecimento e compreensão de certos conceitos. Nenhuma dessas questões leva o aluno à percepção da palavra como unidade portadora de significado e, conseqüentemente, como unidade de apoio para a construção do significado do texto.

Acreditamos que as estratégias empregadas pela maioria dos autores dos livros didáticos para a abordagem do ensino do vocabulário estão sendo tratadas de forma superficial e automatizada. Nesse caso, a proposta da teoria dos Campos Lexicais se faz importante e pode ser um instrumento de ajuda aos professores e alunos, especialmente, no que diz respeito ao enriquecimento e à competência lexical.

A afirmação de Saussure, de que existe o princípio de solidariedade entre as palavras, ou seja, elas estão ligadas por uma rede associativa é corroborada por Trier e Weisgerber, que confirmam esse princípio, afirmando 
não se tratar de simples produto da fantasia humana, e sim o resultado de um esforço para se representar a realidade.

A teoria dos Campos Léxicos diz que as palavras estão internamente ligadas entre si por uma rede de associações. Algumas destas associações são baseadas em sentidos, outras são ligadas pela forma e outras, simultaneamente pela forma e sentido. Saussure afirma que "um termo dado é como o centro de uma constelação, o ponto para onde convergem outros termos coordenados cuja soma é indefinida" (SAUSSURE, 1972, p. 146).

Acreditamos que a Teoria dos Campos Léxicos pode ser um instrumento útil na sala de aula. O vocabulário que se encontra ao final de cada texto, listas de novas palavras, exercícios descontextualizados, memorização quantitativa e outras técnicas utilizadas, pouco auxiliam na organização do léxico em grupos ou subgrupos unidos por algo em comum e diferenciados por traços mínimos.

Retomando Biderman, a autora nos esclarece que

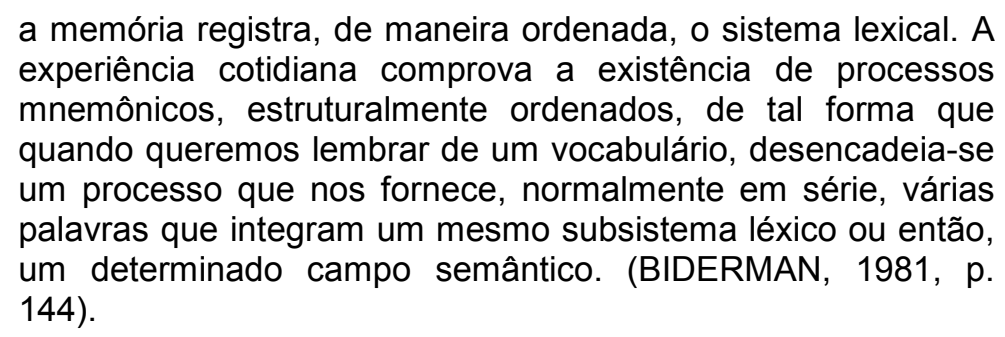

Sabemos que o léxico não está armazenado em nossa memória por ordem alfabética, como nos dicionários. Parafraseando a autora, acreditamos que quando nos referimos a uma palavra, provocamos em nossa memória um processo automático que nos faz também lembrar de muitas outras relacionadas a ela. Por exemplo, a palavra "amor" está interligada a idéia de carinho, admiração, paixão, afeto, namoro, ternura, entre outras. Dessa forma, mais uma vez, reafirmamos a importância dos campos léxicos como estratégia de criação de atividades para o ensino e aprendizagem do vocabulário. 
Para tanto, selecionamos aleatoriamente dois livros didáticos destinados ao ensino de Língua Portuguesa no Ensino Fundamental, analisamos uma pequena amostragem de seus exercícios destinados ao ensino e enriquecimento do vocabulário, sempre respeitando as nomeações dados pelos autores e, em seguida, propusemos algumas contribuições.

Importante citar que não queremos dizer que não há, nos livros selecionados, bons exercícios. Pretendemos, apenas, contribuir propondo atividades que devem ser entendidas como sugestões já que poderão ser adaptadas às diferentes turmas, não foram testadas em sala de aula e, dessa forma, não têm o seu devido caráter científico.

Vale ressaltar que, apesar de não terem sido testadas em sala de aula, a experiência com esse nível de ensino leva-nos a crer que, com uma metodologia eficaz e com muita criatividade, os professores podem adaptá-los em suas turmas e aproveitá-las em suas aulas de vocabulário.

Exercício 1 - (Livro Leitura e produção de textos da Coleção Palavras $-5^{a}$ série, p. 56)

"Somos medo e coragem. Alegria e tristeza. Somos mãe e filha". Você encontrará uma relação de palavras. Distribua-as, em seu caderno, de acordo com a significação em comum que possuem:

\begin{tabular}{|c|c|l|l|}
\hline ALEGRIA & TRISTEZA & MEDO & CORAGEM \\
\hline riso & saudade & pesadelo & calafrio \\
guerreiro & otimismo & engraçado & herói \\
nervosismo & pena & forte & mal-estar \\
tristonho & bravura & diversão & confiante \\
infeliz & desânimo & sorridente & espanto \\
pânico & prazer & brincar & mágoa \\
valente & pavor & desgosto & horror \\
bruxa & aflição & valentia &
\end{tabular}


A apresentação inicial do exercício expõe para o aluno os arquilexemas centrais: Alegria, tristeza, medo, coragem. Interessante que o professor discutisse com o aluno que, nem todas as palavras propostas pelo autor conseguem se enquadrar nos arquilexemas citados. Por exemplo: "nervosismo" está ligado à alegria, tristeza, medo ou coragem? Dessa forma, pretende-se que $o$ aluno perceba algo em comum que une todas as palavras pertencentes a um determinado campo. $O$ autor sugere como resposta que as palavras poderiam estar assim agrupadas:

- ALEGRIA: riso, otimismo, engraçado, diversão, sorridente, prazer, brincar;

- TRISTEZA: saudade,pena, desgosto, tristonho, infeliz, desânimo, mágoa;

- MEDO: pesadelo, calafrio, pavor, nervosismo, mal-estar, horror, espanto, bruxa, aflição, pânico;

- CORAGEM: valente, guerreiro, herói, bravura, forte, confiante, valentia.

A Teoria dos Campos Léxicos propõe um entrelaçamento de relações. Nosso conhecimento de mundo nos faz crer que os lexemas relacionados à alegria são vistos como sendo positivos para o ser humano.

Pensamos, então, a algumas sugestões que seriam pertinentes para que o professor completasse o exercício.

a) Fazer junto aos alunos um levantamento de outras palavras relacionadas ao tema, dividindo-as em categorias ou grupos criados por eles mesmos, tais como: sentimentos, ações, características, ou ainda, substantivos, verbos e adjetivos ou outras categorias sugeridas pelos alunos.

b) Solicitar a criação de pequenos textos, como : "Existem momentos muito tristes em nossa vida. Existem, também, momentos muito alegres. Anote fatos e atitudes que te fazem feliz e infeliz, caracterizando-os com as palavras aprendidas. 
Exemplo: conversar com os amigos: alegria, contentamento.

Ser reprovado na escola: tristeza, desgosto.

Exercício 2 - (Livro Leitura e produção de textos da Coleção Palavras - $5^{\text {a }}$ série, p. 65).

Forme novas palavras: água = aguar, aguapé, aguado, aguacento, desaguar.

$\begin{array}{ll}\text { flor } & \text { rua } \\ \text { lua } & \text { sol } \\ \text { noite } & \text { rio }\end{array}$

Nesse exercício é possível "juntar" todas as formas que um verbo, um substantivo e um adjetivo podem assumir. Isso é possível e fortalece a noção de paradigma.

Voltemos ao exercício: Sua descrição inicial permite verificar que as palavras apresentadas "água, aguar, aguapé, aguado, aguacento e desaguar" têm uma raiz comum.

É importante considerarmos o valor da morfologia no enriquecimento lexical do aluno. Sabemos que o termo está longe de pertencer exclusivamente à ciência lingüística. Pelo contrário, este termo remete a uma disciplina partilhada por várias áreas do conhecimento, da biologia, da tecnologia e está relacionado ao conhecimento das formas.

Ao considerá-la em seu domínio, a lingüística especifica esse enunciado, identificando as formas de análise, os processos geradores de sua existência e transformação e as suas propriedades.

Ainda, com a intenção de contribuir com o docente do ensino fundamental sugerimos atividades como, por exemplo: 
a) Ocasionalmente, a flexão de uma palavra leva a formas que pertencem também a outras palavras. Observe: "Filha, sempre trave (verbo) a porta do carro."; "A bola bateu na trave (substantivo)".

Fenômeno semelhante ocorre com as palavras abaixo:

"Soldado, portaria, cantaria, portas." Para cada uma dessas palavras, faça uma frase em que uma ocorra como verbo e outra como substantivo.

Exercício 03 - (Livro Leitura e produção de textos da Coleção Palavras - $5^{a}$ série, p. 147/151)

"O amor são dois passarinhos a construir a sua casinha". Nesses versos, o que o uso do diminutivo sugere?

Arvorezinha é o diminutivo de árvore. Qual é o diminutivo de:

casa; chapéu; rua; saia; praça; rio; casaco; pincel; sol; parque; porco; estrela.

A formação dos diminutivos, neste exercício, poderia ser uma excelente oportunidade para o enriquecimento lexical do aluno. Procuraremos refletir, sobre os diferentes efeitos de sentido a elas associados.

De acordo com o dicionário eletrônico Aurélio, século XXI, o sufixo -inho é formador de diminutivos e demonstra afetividade (traço natural aos diminutivos). O dicionário acrescenta, ainda, que ele pode demonstrar ironia, a noção de que é muito ou totalmente (velhinho), a noção de força (pilequinho), que é semelhante a algo (urubuzinho), tipo ou variedade (cravinho).

Dessa forma, o objetivo de nossa proposta é mostrar aos alunos a riqueza de significados comparando palavras, descrevendo, exemplificando, buscando relações que possam ser perceptíveis aos alunos. Por exemplo:

a) Compare as palavras abaixo e observe se elas mudam o significado quando acrescentamos o sufixo -inho ou se tratam do mesmo objeto.

Colar/colarinho; calças/calcinhas; corrente/correntinhas; burro/burrinho(peça da mecânica do automóvel) 
Exercício 04 - (Livro Leitura e produção de textos da Coleção Palavras - $5^{a}$ série, p. 150)

Invente uma frase com as palavras cão e animal no diminutivo plural.

O exercício, apesar de solicitar ao aluno que invente frases, poderia ampliar os recursos para a análise dos aspectos nocionais do significado das palavras propostas. Sabemos que o lexema "animal" é hipônimo de "cão", ou seja, há entre animal e cão uma relação que se estabelece na maior especificidade de um deles. Dessa forma, o professor poderia valer-se da oportunidade para mostrar aos alunos que as palavras, se enquadram em conceitos mais ou menos abrangentes. As noções de hiponímia e hiperonímia têm fundamental importância, pois têm a ver com a noção de inclusão e extensão maior ou menor.

A seguir, nossas propostas:

a) Separe, entre os grupos apresentados, aquele termo que apresentam uma significação mais genérica:

a) gato, animal, cachorro, onça

b) caminhão, bicicleta, veículo, carruagem, triciclo.

c) Flor, crisântemo, cravo, rosa, orquídea.

d) Batedeira, eletrodoméstico, geladeira, liquidificador, forno de microondas.

b) Complete as listas abaixo com termos mais específicos:

a) Pedras preciosas:

b) Pássaros:

c) Partes do corpo humano:

d) Nomes de capitais:

e) Fantasias de carnaval:

Exercício 05 e 06 - (Livro Linguagem - criação e interação - 5a série, p. 23/31) 
As duas palavras, entre parênteses, possuem sentido semelhante. Reescreva cada frase, completando-a com a que for mais adequada à situação apresentada.

a) O ser humano torna-se * quando exerce plenamente a cidadania. (livre/solto)

b) Toda criança tem o direito de * educação e formação. (ganhar/receber)

c) Infelizmente, há notícias sobre o * de meninos de rua. (extermínio/extinção)

d) A medicina * é uma boa forma de garantir a saúde. (preventiva/preparatória)

Copie as frases, completando-as adequadamente com as palavras propostas: desamparados/abandonados

a) Alguns bebês são * pelos pais logo após o nascimento.

b) O desemprego deixa muitos trabalhadores *, sem meios para sustentar suas famílias.

entender/perceber

c) Não consigo * por que ainda há tanta miséria.

d) Às vezes, passamos perto de um necessitado sem * a presença dele.

Esse momento seria importante para que os docentes alertem os alunos sobre os fatores que afetam a escolha entre palavras que têm sentido tão próximo. Devem conscientizá-los de que os sinônimos são palavras de sentido próximo, que se prestam, ocasionalmente, para descreverem as mesmas coisas e as mesmas situações. É sabido que não existem sinônimos perfeitos e a escolha entre dois sinônimos acaba dependendo de vários fatores: características regionais, diferenças entre objetos, grau de formalismo da fala, entre outros. Os exercícios acima fazem novamente uma confusão no enunciado, pois sequer apontam ou descrevem esses fatores.

Se, por exemplo, necessitarmos utilizar as palavras "roubo" e "furto", necessariamente teríamos que nos remeter as diferenças de sentido, ou seja, para as pessoas comuns, furto e roubo são exatamente a mesma coisa; para a lei, há uma diferença: no roubo a vítima sofre algum tipo de violência. 
As relações entre os significados das palavras dependem, em princípio do contexto. Observe os exemplos retirados do Dicionário Aurélio, versão eletrônica, século XXI. "Aceito o convite para jantar. No domingo, estou livre", "O cachorro, livre da coleira, mordeu o primeiro que passou"; "As mercadorias estão livres de impostos"; "Parece que o Diabo anda solto", "As roupas soltas Ihe caem melhor"

A princípio "Livre e solto" carregam partes de um significado comum, mas na oração "O ser humano torna-se solto quando exerce plenamente a cidadania", percebe-se que "livre" não é necessariamente sinônimo de "solto".

Dessa forma, poderíamos sugerir atividades que mostrassem aos alunos a riqueza de sentidos quando estamos tratando desse assunto. Por exemplo:

a) Sabemos que as crianças utilizam algumas varetas, cola e papel e constroem, pelo Brasil afora, um brinquedo que voa, segurado por um barbante e enfrentando a resistência do ar. Esse brinquedo recebe vários nomes: papagaio, pandorga, quadrado, pipa, entre outros.

Com seus colegas, faça um levantamento desses nomes que indicam esse brinquedo. Verifique as diferenças: se elas estão ligadas ao formato do brinquedo, se correspondem à construção etc.

Exercício 07 e 08 - (Livro Linguagem - criação e interação - 5ª série, p. 35/37) Qual o significado do verbo "fazer" em cada uma destas frases?

a) Provavelmente o artesão ainda não havia feito doze anos de idade.

b) Podemos fazer uma idéia de sua dedicação.

c) O garoto pediu uma certa quantia pelo tapete, mas acabou fazendo por menos para o freguês.

d) Ele sempre faz descontos em suas mercadorias?

e) O comprador fez um bom negócio.

Identifique o sentido da palavra "prova" no trecho:

“- Eu vi. Mas é a prova de que foi feito à mão, e não em uma máquina." 
( ) competição, ( ) avaliação escolar, ( ) verificação de uma operação matemática, ( ) demonstração da verdade de algo, ( ) experiência, ( ) concurso.

No que diz respeito aos problemas relacionados ao ensino $\mathrm{e}$ enriquecimento do vocabulário é importante ressaltar a importância da necessidade de os alunos do Ensino Fundamental conhecerem e utilizarem adequadamente um número razoável de palavras. Os exercícios acima são um bom exemplo de vários aspectos semânticos a ser ensinado. Ele solicita ao aluno que identifique o sentido do verbo "fazer" e do substantivo "prova" em algumas orações.

A noção de semelhanças e diferenças constitui uma âncora para o ensino do vocabulário. Dessa forma, apesar do livro didático propor contextos diferentes para o emprego das palavras, poderemos deixar claros os distintos traços semânticos abordados.

Nossa contribuição: perguntas como: Qual a diferença do verbo "fazer" nas orações: "Podemos fazer uma idéia de sua dedicação" e "O garoto pediu uma certa quantia pelo tapete, mas acabou fazendo por menos para o freguês."; ou ainda: "As provas de sua inocência serão anexadas ao processo"; "O carro foi submetido a todo tipo de prova."

\section{CONCLUSÃO}

Diante do exposto, fica claro que buscamos, nesse trabalho, uma maneira de oportunizar ao aluno e professor o desenvolvimento de sua criatividade, o seu poder de produção, de dizer com fluência, presteza e precisão aquilo que pensam. Vale ressaltar que defendemos, entre tantas outras para o ensino do léxico, uma metodologia baseada em muita criatividade e que possa buscar na Lexicologia, especialmente na teoria dos campos Léxicos seus fundamentos teóricos, embora essa possibilidade de ensino não deva ser única e nem preencher todas as possibilidades de ensino. 
Certamente em se tratando de pedagogia de línguas, a aquisição do léxico ainda está em fase de pesquisa, embora isto não impeça aos professores de buscarem e se orientarem por novas propostas.

Nosso papel, nesse contexto, não foi o de tomar partido pela primazia de uma teoria em detrimento da outra. O que buscamos foi demonstrar que em qualquer nível de ensino a teoria dos campos léxicos pode contribuir para a adequação do ensino das atividades de linguagem.

Durante a nossa pesquisa apenas assumimos o papel de "professorpesquisador", ou seja, aquele que está sempre disposto a interpretar, compreender e descobrir as "regras" do ensino e aprendizagem da Língua portuguesa.

Em síntese, este estudo vislumbra a existência de uma relação entre a Teoria dos Campos Léxicos e o ensino e aprendizagem da Língua Portuguesa. Por um lado, é claro, não podemos falar de um método $100 \%$ eficaz, mas, por outro, a compreensão de um texto pode ser relativamente mais fácil e prazerosa se o leitor for construindo e reconstruindo o significado das palavras a partir das construções armazenadas na memória e das relações que as palavras mantêm entre si.

Por fim, o que importa, neste estudo, é tomar campo léxico como uma teoria que auxiliará a estratégia de ensino, tendo em vista as relações associativas de idéias, associações sinonímicas e antonímicas, bem como os campos de famílias de palavras. Importante se faz utilizarmos essa teoria em atividades diferenciadas e significativas para os estudantes do Ensino Fundamental.

\section{Referências Bibliográficas}


BIDERMAN, Maria Teresa. A Estrutura Mental do Léxico. In: Teoria Lingüística. Lingüística quantitativa e computacional. Rio de Janeiro: Livros Técnicos e Científicos, 1981, p. 131-145.

COSERIU, Eugênio. Teoria da linguagem e lingüística geral. Rio de Janeiro: Presença; São Paulo: Edusp, 1977.

GECKELER, Horst. Semântica Estructural y Teoría del campo léxico. 2.ed. Editorial Gredos: Madrid, 1976.389 p.

GENOUVRIER, E.; PEYTARD, J. Lingüística e Ensino do Português. Tradução de Rodolfo Ilari. Coimbra: Livraria Almedina, 1973. p. 277-367.

LYONS, John. Semântica Estrutural. Lisboa, Presença, 1974.

POTTIER, Bernard. Linguyistique Générale: théorie et description. Paris, Klincksieck, 1974.

SARGENTIM, Hermínio G. Leitura e Produção de Textos. São Paulo: IBEP, 1998, $191 \mathrm{p}$.

SAUSSURE, F.de. Curso de Lingüística Geral. $3^{a}$ ed. São Paulo: Editora Cultrix, 1972. $271 \mathrm{p}$.

SOUZA, Cássia Garcia; CAVÉQUIA, Márcia P. Linguagem - Criação e Interação. 2.ed. Saraiva: Rio de Janeiro, 1998. 213 p.

TRIER, J. Das sprachliche Feld. Eine Auseinandersetzung. Neue Jahrbuecher fuer Wissenschaft und Jungendbildung, 1934. 